Annuaire suisse de politique de développement

6 | 1987

Annuaire Suisse - Tiers Monde 1986

\title{
Les banques suisses et la crise d'endettement des pays du Tiers Monde
}

Die schweizerischen Banken und die Schuldenkrise der Dritten Welt

Georg Jung

\section{CpenEdition}

1 Journals

Édition électronique

URL : http://journals.openedition.org/aspd/1248

DOI : $10.4000 /$ aspd. 1248

ISSN : 1663-9669

Éditeur

Institut de hautes études internationales et du développement

Édition imprimée

Date de publication : 1 janvier 1987

Pagination : 143-158

ISSN : 1660-5934

Référence électronique

Georg Jung, «Les banques suisses et la crise d'endettement des pays du Tiers Monde », Annuaire suisse de politique de développement [En ligne], 6 | 1987, mis en ligne le 09 mars 2013, consulté le 08 septembre 2020. URL : http://journals.openedition.org/aspd/1248; DOI : https://doi.org/10.4000/ aspd. 1248

Ce document a été généré automatiquement le 8 septembre 2020

(c) The Graduate Institute I Geneva 


\section{Les banques suisses et la crise d'endettement des pays du Tiers Monde}

Die schweizerischen Banken und die Schuldenkrise der Dritten Welt

Georg Jung

\section{NOTE DE L'ÉDITEUR}

En français, résumé seulement. Lire l'article original en allemand dans Schweizerisches Jahrbuch für Entwicklungspolitik : « Die schweizerischen Banken und die Schuldenkrise der Dritten Welt », http://sjep.revues.org/1061.

\section{RÉSUMÉS}

La crise financière que le Mexique a connue en 1982 a provoqué une opération de sauvetage internationale de grande envergure. Le Mexique et une vingtaine d'autres pays débiteurs ont dû rééchelonner leurs dettes privées et publiques. Seule la concertation des actions a permis d'éviter l'effondrement des relations de crédit internationales. Grâce aux accords de rééchelonnement et à l'octroi de nouveaux prêts, les pays débiteurs ont pu procéder à certains ajustements qui ont apporté une amélioration passagère (jusqu'en 1985), quoique au prix de coûts sociaux élevés pour la population. En fait, d'un point de vue général, la situation s'est à nouveau dégradée en 1985 . Les banques suisses ont adopté une attitude plus réservée que les autres pays en ce qui concerne l'octroi de crédits aux pays du Tiers Monde; extrêmement actives sur le plan des transactions interbancaires, elles sont en mesure de procurer des capitaux à court terme aux banques 
commerciales internationales. Une crise financière internationale affecterait donc les banques suisses avant tout sur ce plan-là. D’une manière générale, les banques suisses ont réagi favorablement à la proposition du ministre des finances américain, M. Baker, qui consiste à intensifier la capacité de croissance de quinze pays en développement fortement endettés. En outre, les banques suisses ont noté avec satisfaction que le gouvernement américain semblait reconnaitre que la crise internationale de l'endettement revêt aussi un aspect politique. Le plan Baker prévoit notamment d'augmenter les crédits accordés par les banques commerciales aux pays débiteurs. Les banques suisses ont pris position à plusieurs reprises, réclamant une plus grande latitude pour ce qui a trait aux négociations sur le rééchelonnement des dettes. En effet, la pratique actuelle qui consiste à apporter une contribution financière uniquement sous forme d'argent frais, est ressentie par les banques comme une contrainte inutile. A leur avis, une option possible serait d'accorder un moratoire sur les intérêts. Par ailleurs, les banques aimeraient pouvoir attribuer davantage de crédits commerciaux, car ils sont importants pour les échanges commerciaux des pays en voie de développement et offrent davantage de garanties que les simples crédits financiers. Les banques admettent qu'un système efficace de relations de crédits n'entraîne pas nécessairement un transfert de ressources vers les pays en voie de développement, ce qui d'ailleurs apparaît souhaitable en vertu des critères de politique du développement. L'auteur conclut son article en énumérant les points qui lui paraissent essentiels dans le présent contexte: le capital prêté doit être évalué au cours du marché et remboursé comme tel; les pays débiteurs sont tenus de mener une politique économique cohérente ; l'aide officielle au développement doit combler les déficits financiers qui subsistent encore. 